\title{
Possibilities of Using AR and VR Technologies in Teaching Mathematics to High School Students
}

\author{
Tetiana A. Vakaliuk ${ }^{1, *}$, Larysa D. Shevchuk ${ }^{2}$, Borys V. Shevchuk ${ }^{2}$ \\ ${ }^{1}$ Department of Software Engineering, Faculty of Information and Computer Technologies, Zhytomyr Polytechnic State University, \\ Ukraine \\ ${ }^{2}$ Mathematics, Computer Science, and Teaching Methods Department, Hryhorii Skovoroda University, Ukraine
}

Received July 19, 2020; Revised September 16, 2020; Accepted September 29, 2020

\section{Cite This Paper in the following Citation Styles}

(a): [1] Tetiana A. Vakaliuk, Larysa D. Shevchuk, Borys V. Shevchuk, "Possibilities of Using AR and VR Technologies in Teaching Mathematics to High School Students, "Universal Journal of Educational Research, Vol. 8, No. 11B, pp. 6280 6288, 2020. DOI: 10.13189/ujer.2020.082267.

(b): Tetiana A. Vakaliuk, Larysa D. Shevchuk, Borys V. Shevchuk (2020). Possibilities of Using AR and VR Technologies in Teaching Mathematics to High School Students. Universal Journal of Educational Research, 8(11B), 6280 - 6288. DOI: 10.13189/ujer.2020.082267.

Copyright $\bigcirc 2020$ by authors, all rights reserved. Authors agree that this article remains permanently open access under the terms of the Creative Commons Attribution License 4.0 International License

\begin{abstract}
Difficulties at the beginning of studying stereometry in 10 classes are well known from school practice. One of the main reasons for this is poorly developed spatial thinking and imagination. Therefore, the article describes some possibilities of using virtual and augmented reality in the process of teaching mathematics to students in 10-11 classes. It is established that pedagogical research in the field of theory of teaching mathematics should go this way. Undoubtedly, the lessons of mathematics with the addition of reality have a huge future in the field of education. The extensive use of virtual and augmented reality technologies in teaching mathematics proves the effectiveness and it is an attractive motivation for students. The use of augmented reality can be implemented in the teaching of mathematics from primary schools to universities. The object of research is the process of the formation of spatial imagination using virtual and augmented reality technologies in the process of teaching mathematics. The subject of the study is the environment of virtual and augmented reality. Research methods are analysis of publications on the problem, generalization of domestic and foreign experience, theoretical analysis, system analysis, systematization, and generalization of facts and patterns of research for the formation of spatial thinking using virtual and augmented reality environments, substantiation of the main conclusions. In our opinion, it is best to use free and well-made software such as ROAR AR for the Android operating system. Even in universities, it is advisable to use
\end{abstract}

augmented reality systems in the training of future mathematics teachers, as they will be able to stop the decline in the popularity of mathematics studies in secondary and high schools by using such innovative teaching methods in their future pedagogical activities.

Keywords Augmented Reality, Virtual Reality, Educational Technologies

\section{Introduction}

Today, without the use of information technology, there is no teaching of any subject and mathematics as well. Mathematics, as a separate branch of knowledge, has a special conceptual apparatus and research methods and it is one of the complex subjects. Difficulties at the beginning of studying of stereometry in 10 classes are well known from school practice. One of the main reasons for this is poorly developed spatial thinking and imagination. Students are occasionally acquainted with spatial figures, in particular with various geometric bodies, in preschool and in primary school. In grades 5-6 of primary school, they have already clearly studied a rectangular parallelepiped, cube; how to calculate their volumes, areas of bases, faces, calculate the volume of a sphere by the formula. In recent years, new goals and ideas for teaching mathematics at school have been increasingly discussed, 
original concepts have been proposed, and new textbooks on the school mathematics course have been considered. One of the ideas is the use of virtual and augmented reality (VR and AR) technologies, which creates unique opportunities in education. By using the data of AR and VR technology in the process of teaching mathematics, supplementing them with appropriate visual information, you can build a visual model of educational material. As a result, students' spatial imagination is developed, which enhances their deep understanding of processes, properties, and proof of theorems. Augmented reality (AR) is a common reality in which digital graphics are added. Unlike virtual reality, which requires complete immersion in a virtual environment, augmented reality uses the environment around us and simply superimposes on its image certain virtual information, such as graphics, text, $3 \mathrm{D}$ models, and the reaction to interacting with them.

\section{Materials and Methods}

The study of the problems of introducing augmented reality in the educational process in practical classes in various subjects at different times was considered by leading scientists of the world. They are Avdoshyn A. [12], Azarian A. [11], Azarian V. [11], Golovin K. [12], Gryshkun A. [14], Hollerer T. [9], Schmalstieg D. [9], Zelinska S. [11], in particular in the study of mathematics Cardoso T. [2], Coimbra M. T. [2], Delgado L. [3], Dillingerova M. [6], Gunkaga J. [5], Kaufman H. [4], Korenova L. [5], Korenova L. [6], Korontsi Babinska M. [6], Mateus A. [2], Schmalstig D. [4], Thomas N. [10], etc.

Prospects for the use of augmented reality in education were considered by Popel M. [7], Shishkina M. [7], Kravchenko Yu. [16], Lezhebokov A. [16], Pashchenko S. [16], Mishina A. [19], Shabeliuk O. [22]. Features of software development using AR in their works were analyzed by Grishkun A. [14], Osadchii V. [21], Kruglyk V. [21], Prokofiev E. [21], Serdiuk I. [21], Koshelnikov V. [21].

M. Coimbra, T. Cardoso, A. Mateus consider augmented reality as an opportunity to expand the teaching and learning of mathematical disciplines in the process of training Portuguese students of polytechnic universities [2].

Yu. Kravchenko, A. Lezhebokov and S. Pashchenko, who explore the possibilities of using augmented reality technologies in education, believe that this technology opens new horizons in education and provides the ability to add contextual information for real objects and visualization of educational material [16].

L. Korenova and J. Gunkaga, who explore the use of augmented reality technology using mobile technology in the mathematical education of future primary school teachers, argue that these technologies make learning more attractive, as well as increase students' motivation to understand mathematical concepts [5].

In his study, Mehmet Fatih Özcan, Âdem Özkan, Nurullah Şahin have aimed to determine students' academic success levels and their satisfaction through the use of augmented applications in Ottoman Turkish reading in which students have difficulties. According to his findings, it has been observed that the use of augmented reality in education and training environment has positive contributions to students' success and satisfaction [26].

The purpose of study Yi-Chen Hsu is to integrate the virtual reality of information technology into the teaching of a system of linear equations in three unknowns in high school mathematics and to explore the learning motivation and effectiveness of students after digital teaching. It is found from the experimental results that the VR has the effect of improving students' learning motivation and learning effectiveness in the digital teaching of mathematics [27].

The object of research is the process of the formation of spatial imagination using virtual and augmented reality technologies in the process of teaching mathematics. The subject of the study is the environment of virtual and augmented reality.

Research methods are analysis of publications on the problem, generalization of domestic and foreign experience, theoretical analysis, systems analysis, systematization, and generalization of facts and patterns of research for the formation of spatial thinking using virtual and augmented reality environments, substantiation of the main conclusions.

\section{Results}

There are many augmented reality software applications. Consider in more detail AR - and VR - technologies for teaching mathematics.

VR Math is a free English-language application that helps students understand spatial shapes and teach teachers 3D geometry. If it is possible to use virtual glasses, and then go to the VR view; if not, you can try $3 \mathrm{D}$ or AR modes. After opening the program, you can choose a role in the classroom: teacher (left side) or student (right side).

Having chosen the role of a teacher, you need to quickly register and create a virtual audience. You can also invite students by sharing your class ID.

Using this application, you can add class assignments so that students can work on them. Highlight the edges, vertices, different parts of solid space and your students can also see them (Fig. 1). This method is effective when using VR Math in the classroom. Later, according to the developers, they plan to add homework and statistics to the application. A short demo of tasks is currently 
available, but more tasks will be available in the future update.

Students have the opportunity to join a class or go at their own pace and choose self-study. More updates with updates will be added to the self-learning mode.

NeoTrie VR (http://virtualdor.com/NeoTrie-VR/) allows you to create, manipulate, and interact with geometric objects in three-dimensional space and models of different types. It also includes some activities and games in 3D geometry (Fig. 2), and more importantly, it allows you to design many more activities on demand.

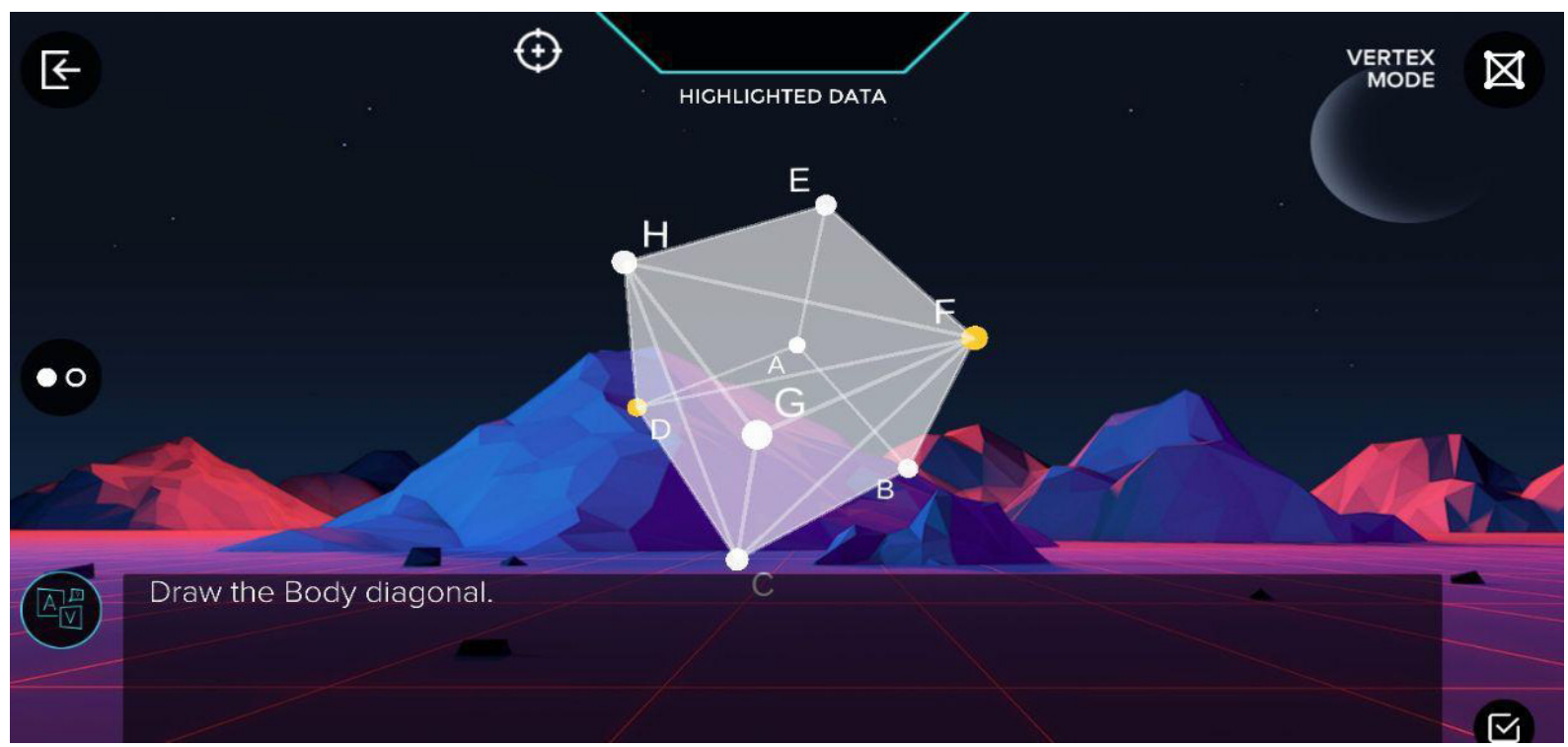

Figure 1. Study of lines of spatial figures in the VR Math environment

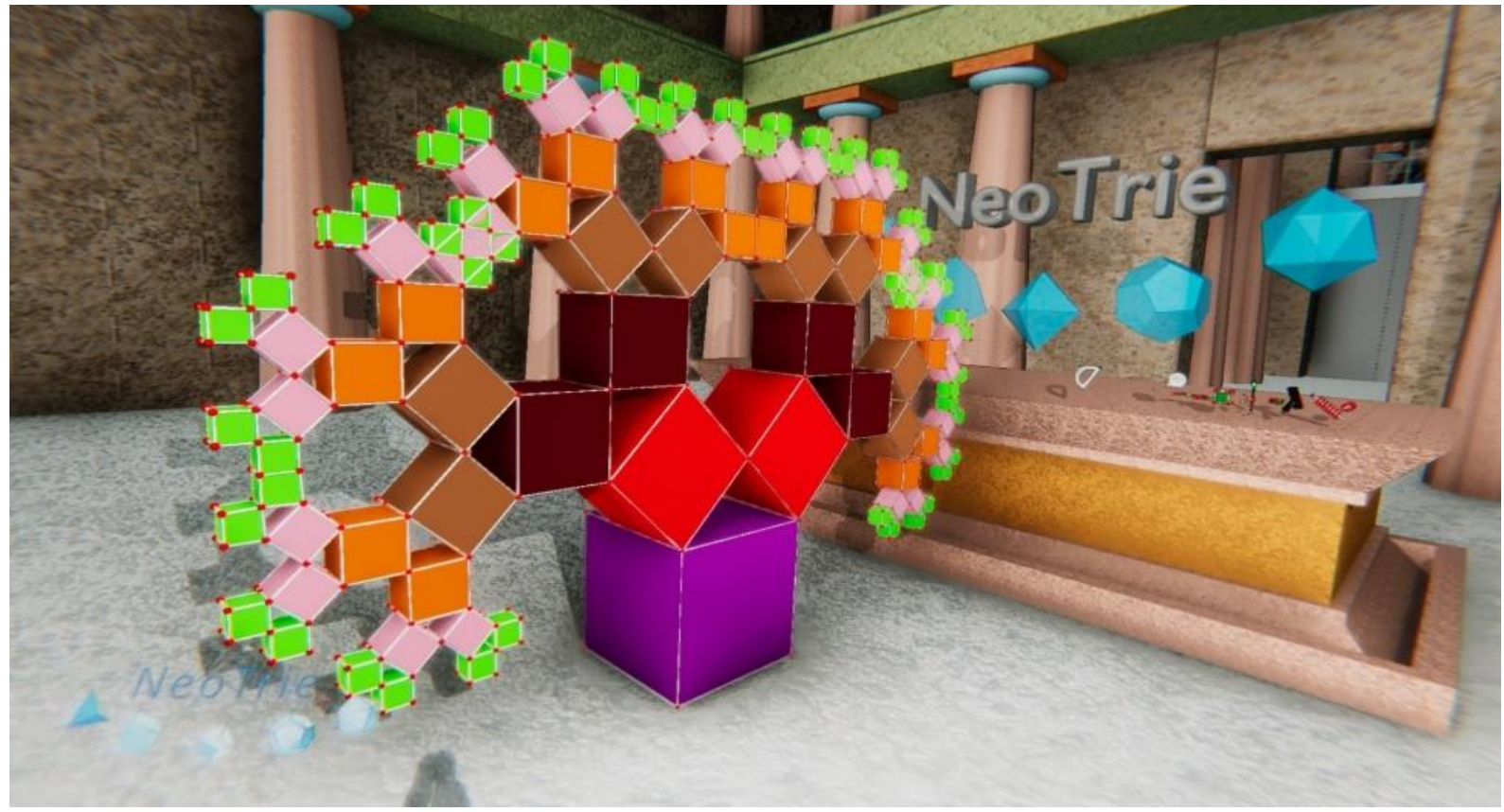

Figure 2. Geometry study environment in NeoTrie VR 


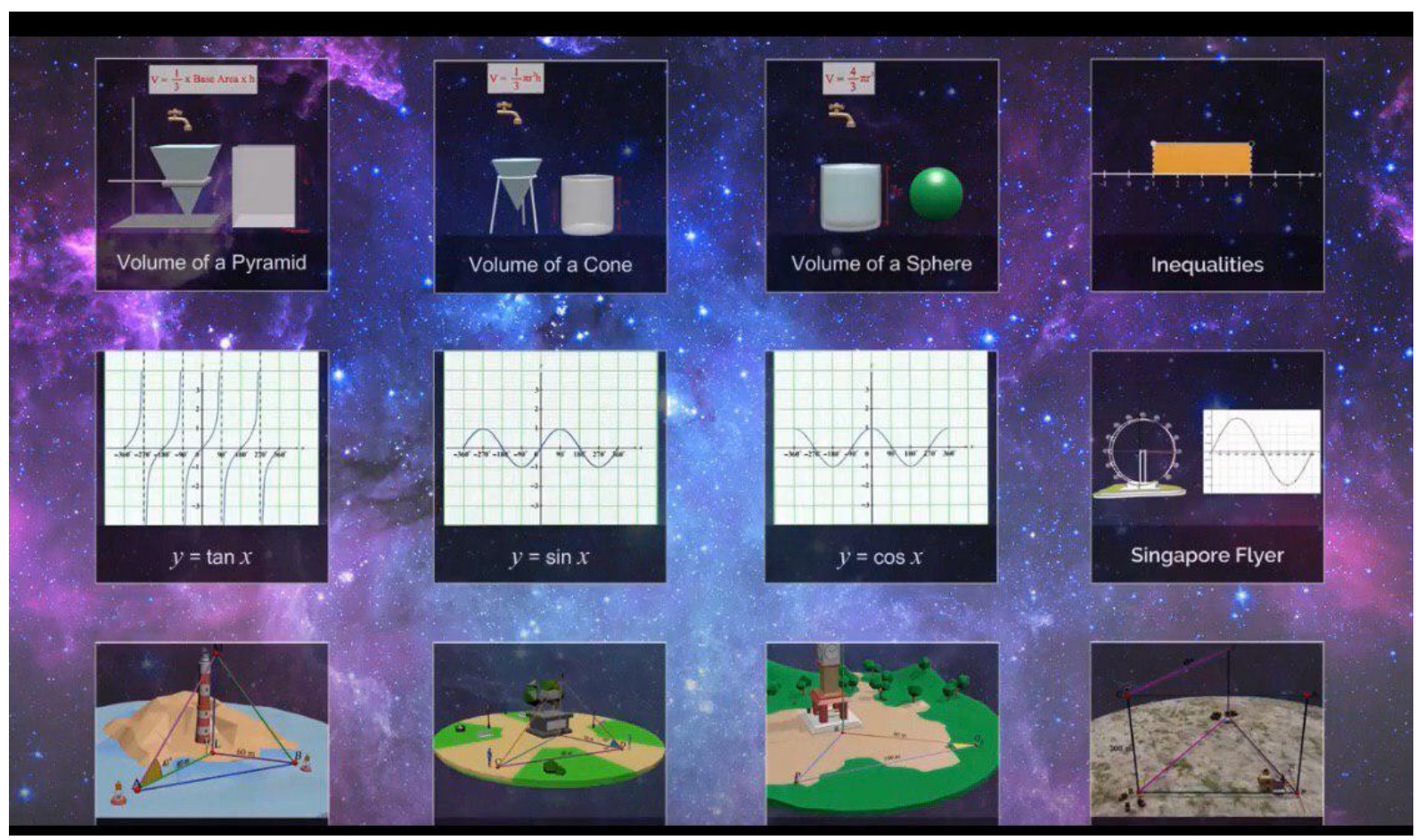

Figure 3. Math VR environment

Another interesting application is Math VR • (https://www.ace-learning.com/app/math-vr), which • includes virtual reality (VR) and augmented reality (AR), allowing students to see how abstract mathematical objects work in a three-dimensional (3D) environment (Fig. 3.). The purpose of the application, which is beyond textbooks, is to seek the development of tasks and examples that inspire and equip young people with tools for personal research and inventions or further education in science, technology, engineering, and mathematics (STEM). The application is easy for students to master; in its environment you can create different classes of geometric shapes, which led to its spread and use in schools in the United States and Europe. However, the big disadvantage is that the application is paid.

Geo-AR (https://geoar.sk-global.biz/) is a tool that will help you better study 3D geometry using augmented reality technology. The $3 \mathrm{D}$ shape of the object will be placed in the real world. By placing your model on the table, you will be able to view all its aspects (Fig. 4).

Features of the Geo-AR application are as follows:

- construction of a point and their connection together;

- automatic recognition of the hidden line and its transformation into a dotted line;

- construction of perpendiculars, parallels, segments, etc; adding an inscription to a line or corner;

- move, scale, rotate the model to see all its aspects;

- dissemination of construction details in real-time;

- $\quad$ Save and share your model with others.

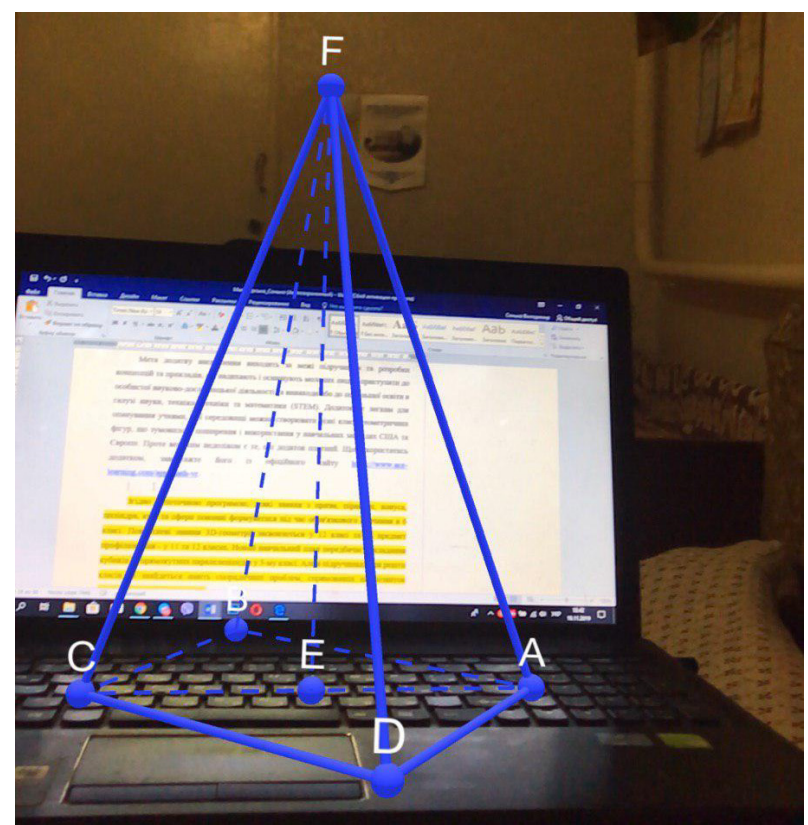

Figure 4. Interactive pyramid model in Geo-AR environment 
With Shapes 3D Create Geometry AR (https://shapes.learnteachexplore.com/shapes-3d-geometry -learning/\#try-now) you can build shapes on your table in augmented reality (Fig. 5).

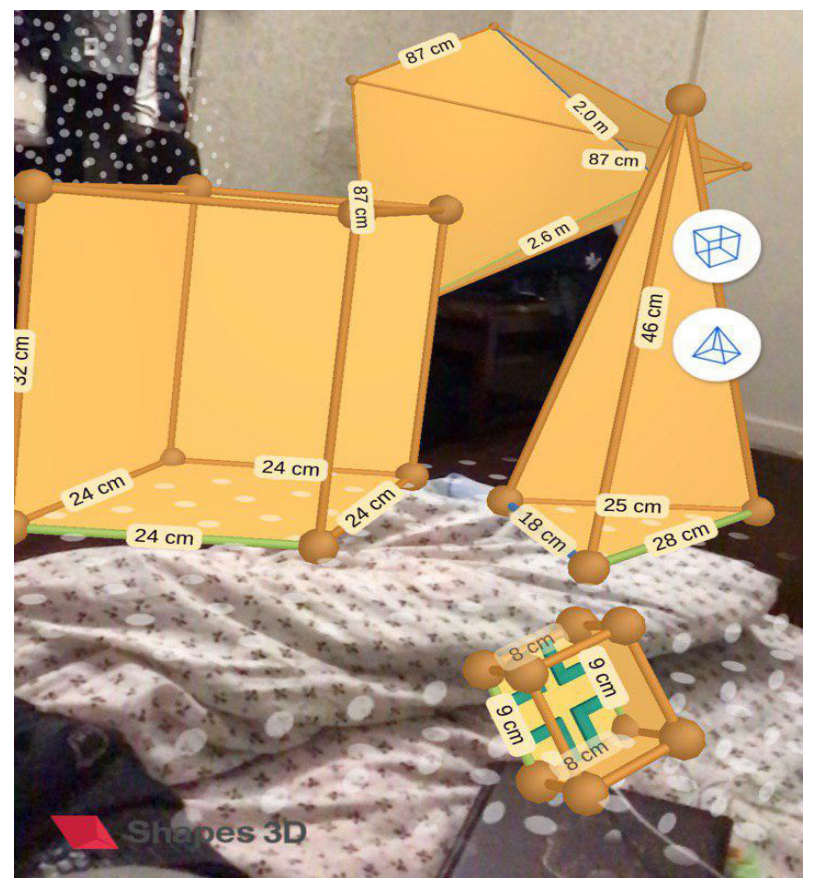

Figure 5. Construction of spatial figures in the environment Shapes 3D

Using this application in the classroom, the teacher can do the following in the program:

- construction of spatial figures on the floor, table, or walls;

- determining the exact dimensions of these figures;

- placement of spatial figures depending on each other;

- construction of the main two-dimensional figures: square, rectangle, and different types of triangles equilateral, isosceles, and rectangular.

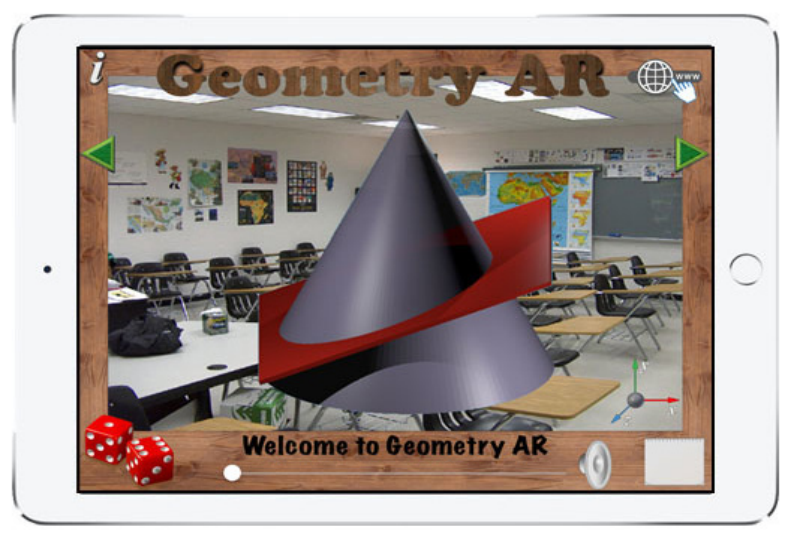

Figure 6. Geometry AR environment

Another equally interesting application is Geometry AR (https://www.venturaes.com/iosapps/geometryar.html)

(Fig. 6). This tool is designed to view and study geometric shapes using augmented reality technology. In the real world, students will be able to see bodies of rotation and polyhedra, actually bypassing the figure to view all sides.

Geometry AR is suitable for math classrooms where the concepts of geometry are studied. Augmented reality adds a level of interest and motivation that will stimulate young people to further research.

Also, the following objects are present in this program: point, ray, segment, line, angle, arc, parallel lines, perpendicular line, intersecting lines, circle, and triangles: acute, rectangular, obtuse, right; square, parallelogram, trapezoid, prism, cylinder, pyramid, cone, sphere, polyhedron, torus, ellipse, parabola, and hyperbola.

Using Geometry AR offers the following capabilities

- get acquainted with information about the main geometric shapes and their properties;

- the appendix presents interesting facts about each of the figures;

- $\quad$ view shapes, moving around them;

- view information about important concepts of geometry or using synthesized speech, listen to this information;

- Available for iPad only.

You can also use augmented reality platforms to learn geometry, which can function as a standalone application or as part of a client-server architecture. The generated code will correspond to the client part of the system, but the presence of the server code is not required for its operation. Any user will be able to run this application in their browser and create their augmented reality.

ROAR is a cloud platform that allows you to create different types of objects using Augmented Reality technology.

With ROAR AR, you can scan and interact with interactive objects created by yourself and others. To do this, download the program and scan the images that should already be created, or view the ARKIT and WebAR created by the ROAR platform.

Today, the ROAR AR platform (http://www.theroar.io) is in the trend of categories, which allows you to easily and quickly create and share stunning AR creations. In addition to the site, you can also use the online application for iOS and Android (Fig. 7).

The ROAR editor makes creating and sharing AR easy for anyone and requires no programming or technical skills. More than 10,000 packages are currently available in the US ROAR database. ROAR is designed to develop educational, commercial, and business projects. Enhanced images allow you to create $\mathrm{AR}$ applications that can match specific $2 \mathrm{D}$ images, such as creating an object or movie. The user can bind virtual objects to specific trackers to ensure that the relationship between the virtual object and the tracked remains stable even as the device moves around. This means that if the user places a virtual object on their desktop, ARCore will adjust the position of the plane associated with the desktop, so that the 3D object will remain on top of the table. 


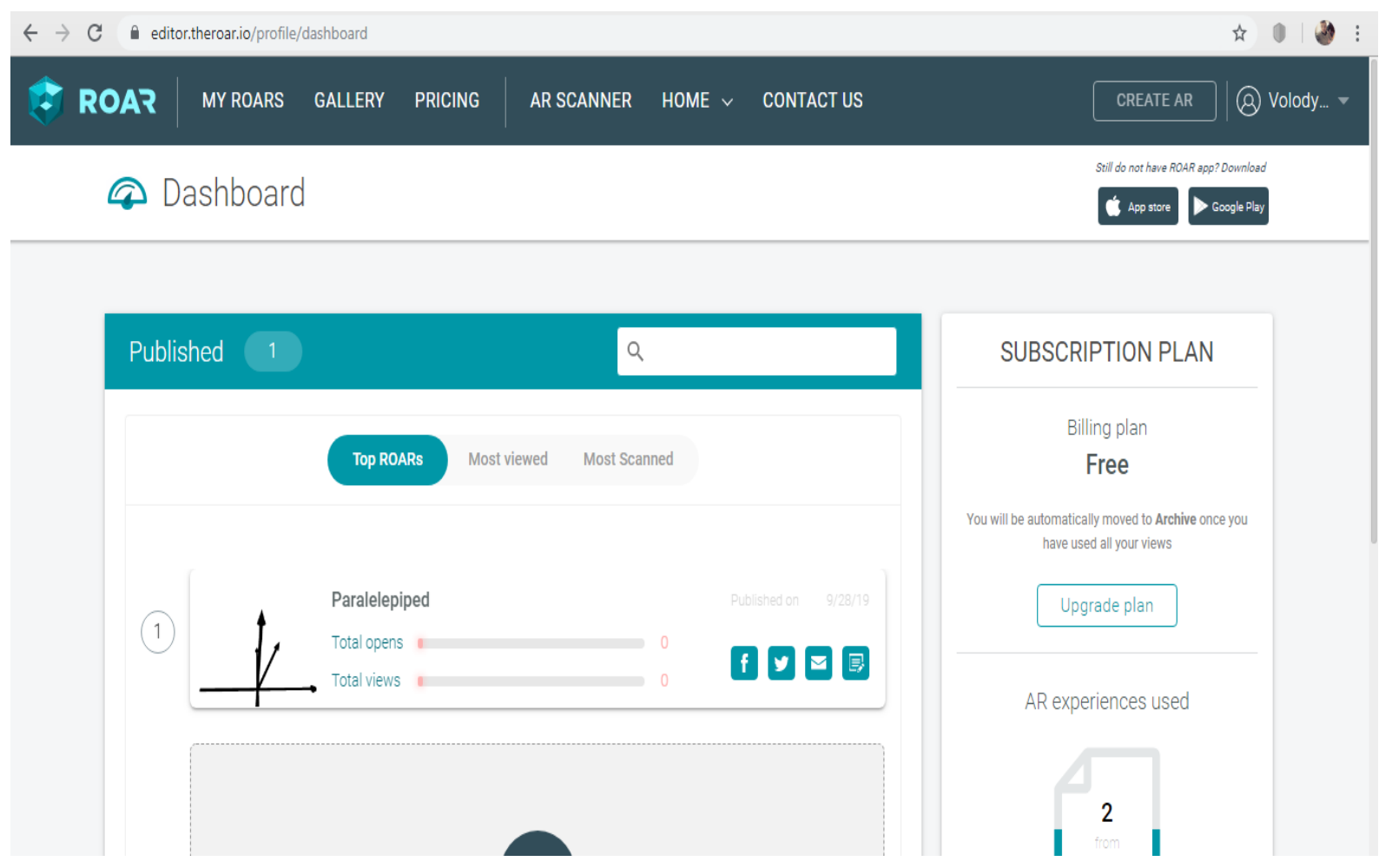

Figure 7. ROAR AR website and smartphone app

Considering the application as a means of creating a learning process, it is worth noting the methodological features of ROAR AR:

- the software can be used both at school in various forms of classes and at home for self-study and with various computer equipment;

- the use of ROAR AR allows students to quickly and efficiently acquire mathematical knowledge and skills, increases the level of memorization of the material;

- increases the degree of motivation and interest of students, providing opportunities for creative tasks and organization of project work;

- modeling and visualization promote better learning of geometric concepts.

- the use of ROAR AR offers an opportunity to expand the boundaries of traditional (classroom) learning by transferring it to a mobile learning environment.

To create augmented reality objects, after registration you need to click "Create AR" in the upper right corner. In the window that opens, you can create:

- $\quad$ target image (AR experience based on target images and markers. You need to scan the image to unlock and detect AR content);

- $\quad$ ARKit \& ARCore (based on creating the impression of $\mathrm{AR}$ and placing various $3 \mathrm{D}$ objects and animations in the physical world);

- WebAR (an AR experience that works from a link and can be viewed through the Safari browser (iOS only)).

The use of ROAR AR in the educational process enables the teacher to incorporate augmented reality content into their projects, books, events, and lessons; create digital learning materials with augmented reality content (figures, advertising and visualize 3D objects and various inscriptions on objects with any visual image marker); research by creating interactive games (include photos, videos, text, audio, 3D models of motion graphics with chromakey and notifications based on geolocation;); view and share via AR Kit, Facebook3D and WebAR. 


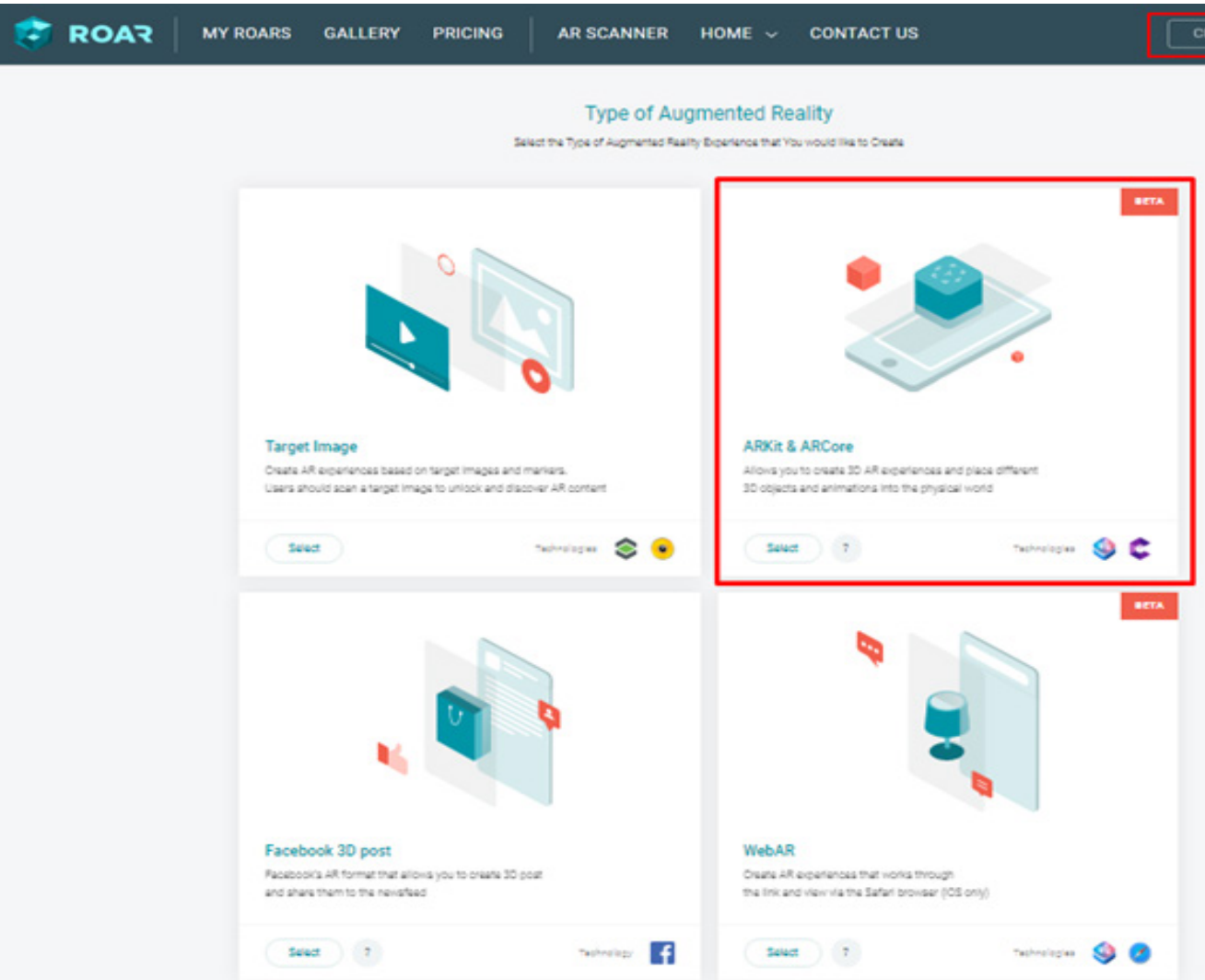

Figure 8. Types of augmented reality in ROAR

Educators can develop educational resources for the classroom to provide digital immersion, engaging content, and student interaction.

To save the created objects in the AR environment, you need to click on the "Save" button (Fig. 9) and they will be saved in the collection folder "My ROARS".

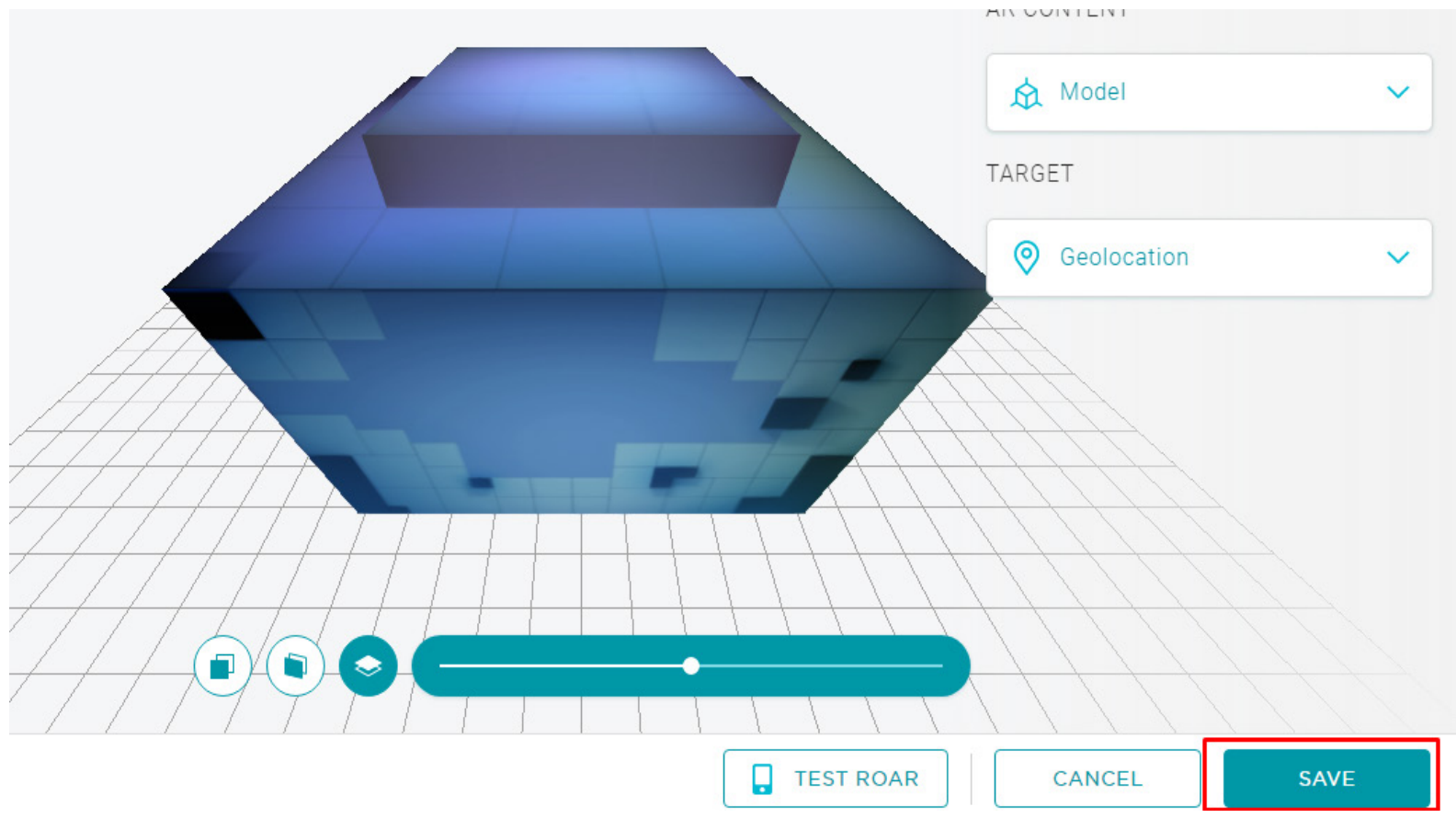

Figure 9. Saving the object in the AR environment 

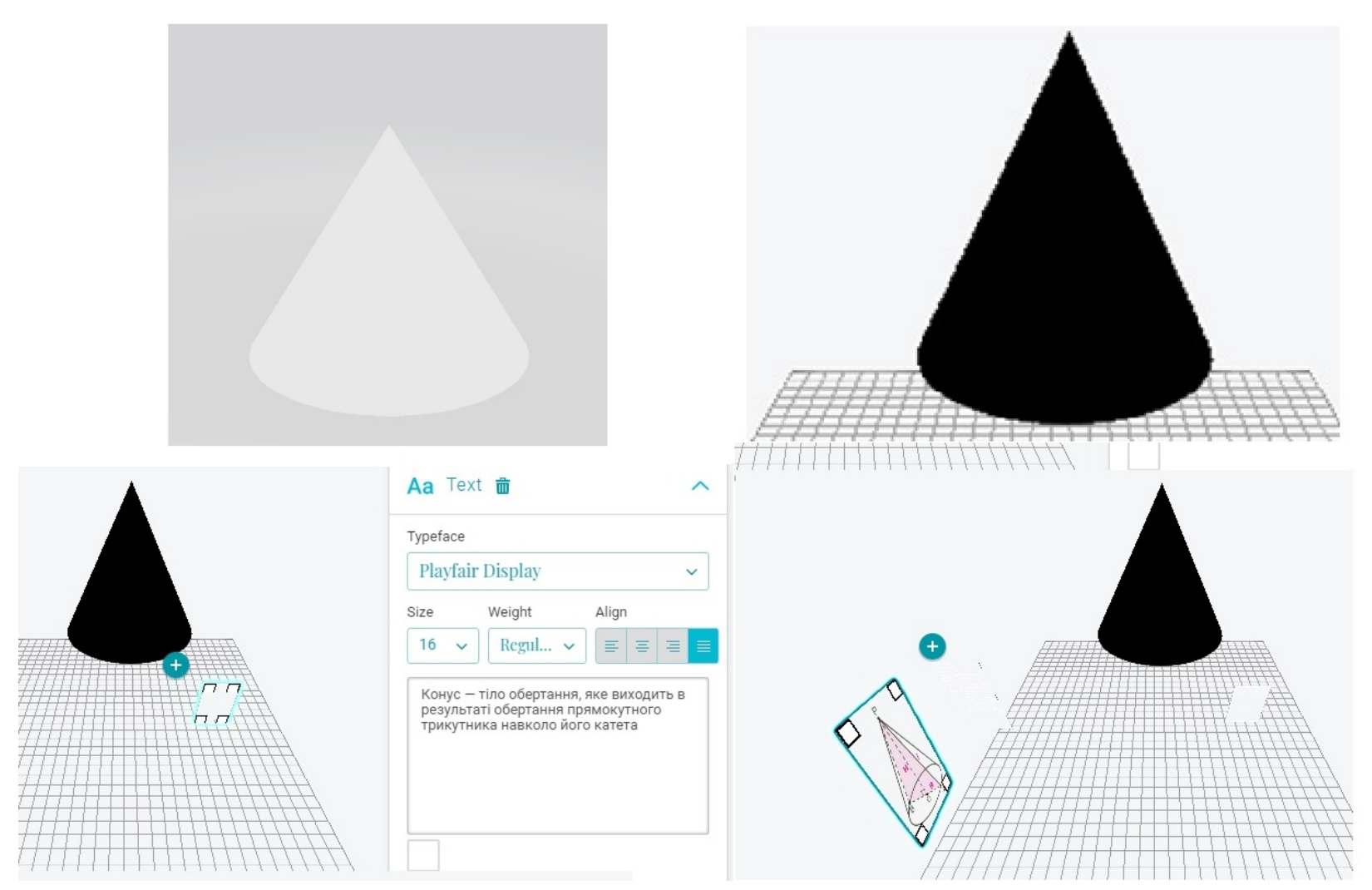

Figure 10. Cone transfer and image adjustment in ROAR AR environment

We will demonstrate the creation of a cone in the AR environment and explore information about it using the ROAR and a ready-made 3D model from Windows 10 . Let us create a transparent cone. Use the "3D objects" button and add a cone to the AR environment (Fig. 10).

Add a definition of the concept of the cone with the button "Text", select the size 16, align the width, and make it white. Let us transfer the image of a cone with its elements to the real environment, having used the button "Photos". Having added some details of the description of the image, we will view the information on a cone in the augmented reality.

Displays of 3D objects made with the help of the ROAR AR program increase their clarity and understanding, as well as provide greater interest for students in the process of learning geometry.

\section{Conclusions}

The use of virtual and augmented reality applications in teaching mathematics to both students raises many questions. Experience shows that pedagogical research in the field of theory of teaching mathematics must go this way; undoubtedly, the lessons of mathematics with the addition of reality have a huge future in education. The extensive use of virtual and augmented reality technologies in teaching mathematics proves the effectiveness and it is an attractive motivation for students. The use of augmented reality can be implemented in the teaching of mathematics from primary schools to universities. At the same time, there is a strong need for good quality electronic materials and math programs for this type of learning. In our opinion, it is best to use free and well-designed software such as ROAR AR for the Android operating system. Even in universities, it is advisable to use augmented reality systems in the training of future mathematics teachers, as they will be able to stop the decline in the popularity of mathematics studies in secondary and high schools by using such innovative teaching methods in their future pedagogical activities.

\section{REFERENCES}

[1] Azuma R., Billinghurst M., Klinker G., Special section on mobile augmented reality. Computers \& Graphics, 35(4), 12. 2011.

[2] Coimbra M.T., Cardoso T., Mateus A., Augmented reality: an enhancer for higher education students in math's learning?, Procedia Computer Science, 67, 332-339, 2015.

[3] Delgado, Laura. Augmented Reality as a Didactic Resource for Teaching Mathematics. Applied Sciences. 10. 2560, 2020.

[4] Kaufmann H., Schmalstieg D. Mathematics And Geometry Education With Collaborative Augmented Reality, 2003, $1-87$ 
[5] Korenova L., Guncaga J., Augmented reality in mathematics education for pre-service teachers in primary level. In: APLIMAT: 17th Conference on Applied Mathematics. Bratislava: STU, 2018, 597-605.

[6] Koronci Babinska, Martina \& Dillingerova, Monika \& Korenova, Lilla. Augmented Reality and Future Mathematics Teachers, 236-263, 2019

[7] Maiia V. Popel, Mariya P. Shyshkina The Cloud Technologies and Augmented Reality: the Prospects of UseAugmented Reality in Education: Proceedings of the 1st International Workshop on Augmented Reality in Education - Kryvyi Rih, Ukraine, October 2, 2018. 61-65.

[8] Nordahl, T., Egelund, N., Nordahl, S. \& Sunnevåg, A.-K. Culture for Learning T1. Hedmarken. Hamar: Senter for praksisrettet utdanningsforksning (practice-based education research center), 2017.

[9] Schmalstieg D., Hollerer T., Augmented reality: principles and practice. Addison-Wesley Professional, 2016, 75-86

[10] Thomas N. Exploring the Use of VR Technologies in Mathematics Class. Online available from https://vreducation.no/pdf/vr-maths-report-EN.pdf

[11] Zelinska, Snizhana, Azaryan, A.A. and Azaryan, V.A. Investigation of Opportunities of the Practical Application of the Augmented Reality Technologies in the Information and Educative Environment for Mining Engineers Training in the Higher Education Establishment Proceedings of the 1st International Workshop on Augmented Reality in Education Kryvyi Rih, Ukraine, October 2, 2018 (2257). 204-214.

[12] Avdoshin A. S., Zaberzhinsky B. E., Golovin K. Yu. Analysis of the possibilities and prospects of using augmented reality in theory and practice. Actual problems of science, economics, and education of the XXI century: mater. II International scientific and practical. conf., Samara, March 5 - September 26. 2012

[13] Breus I.A. Development of spatial thinking of students in terms of obtaining additional mathematical education / I.A. Breus / international scientific journal "Innovative Science" No. 12-3 / 2016

[14] Grishkun A. V. Terminological peculiarities of studying the technology of augmented reality in teaching computer science. Bulletin of the Moscow City Pedagogical University. Series "Informatics and informatization of education", 2016, No. 4 (38). 93-100.

[15] Kravtsov A.A. Using augmented reality technology to visualize a virtual object in a real interior, Polythematic network electronic scientific journal of the Kuban State Agrarian University, Vol. 10, 2012, 724-733, Online available from: https: //ej.kubagro.ru/2012/10/pdf/54.pdf

[16] Kravchenko Yu. A. Features of the use of augmented reality technology to support educational processes / Yu. A. Kravchenko, A. A. Lezhebokov, SV Pashchenko / Open education. 2014. No. 3. 49-54.

[17] 17. Mayer P., Klinker G., Tonnis M. Augmented reality for teaching spatial relationships. International Journal of Arts and Sciences. 2009. Issue. 11, No. 3. 115-122.

[18] Matsokin ID Pakhomova IM Author's mobile applications with augmented reality for the educational process. Source of pedagogical innovations Digital space of teaching natural and mathematical disciplines: scientific and methodical magazine. Issue №4 (28), 2019

[19] Mishina A. V. The concept of using augmented reality systems in teaching a foreign language to preschool children. Collection of materials of the Annual international scientific and practical conference "Education and training of young children." 2016. No. 5. 772-773.

[20] Modlo E.A. The use of augmented reality technology in a mobile-oriented university learning environment / E.A. Modlo, Yu. V. Yechkalo, S.O. Semerikov, V.V. Tkachuk. Scientific notes. Issue 11. Series: Problems of methods of physical-mathematical and technological education. Part 1., 2017, 93-100.

[21] Peculiarities of AR program development for object placement on the map / V.V. Osadchy, V.S. Kruglyk, E.G. Prokofiev, I.M. Serdyuk, V.V. Koshelnikov / Computer science. Bulletin of Mykhailo Ostrogradskyi, Issue 2/2019 (115), 134-139.

[22] Shabelyuk O.V. The use of augmented reality technology in the distance educational process. Bulletin of the Taras Shevchenko National University of Kyiv. Series: Physical and Mathematical Sciences. 2014. No. 2. 215-218.

[23] Shevchuk L.D. Educational potential of web-oriented systems of computer mathematics. Shevchuk. The computer at school and family. Scientific and methodical magazine, 2015. Issue 1 (121). 33-38

[24] Svitlana I. Pochtoviuk, Tetiana A. Vakaliuk, and Andrey V. Pikilnyak. Possibilities of application of augmented reality in different branches of education. Proceedings of the 2nd International Workshop on Augmented Reality in Education, 2019. 92-106. CEUR-WS.org, Online available from http://www.ceur-ws.org/Vol-2547/paper07.pdf

[25] Iatsyshyn, Anna V., Kovach, V.O., Romanenko, Ye.O., Deinega, I.I., Iatsyshyn, Andrii V., Popov, O.O., Kutsan, Yu.G., Artemchuk, V.O., Burov, O.Yu., Lytvynova, S.H.: Application of augmented reality technologies for the preparation of specialists of the new technological era. In: Kiv, A.E., Shyshkina, M.P. (eds.) Proceedings of the 2nd International Workshop on Augmented Reality in Education, 2019, CEUR Workshop Proceedings 2547, 181-200. Online available from http://ceur-ws.org/Vol-2547/paper14.pdf

[26] Mehmet Fatih Özcan, Âdem Özkan, Nurullah Şahin: The Influence of the Augmented Reality Application on Students' Performances in Ottoman Turkish Readings. Universal Journal of Educational Research Vol. 5(12B), pp. 27 - 33. DOI: 10.13189/ujer.2017.051403

[27] Yi-Chen Hsu: Exploring the Learning Motivation and Effectiveness of Applying Virtual Reality to High School Mathematics. Universal Journal of Educational Research Vol. 8(2), pp. 438 - 444. DOI: 10.13189/ujer.2020.080214

[28] Tetiana A. Vakaliuk, Dmytro S. Antoniuk, and Vladimir N. Soloviev: The state of ICT implementation in institutions of general secondary education: a case of Ukraine. Proceedings of the 7th Workshop on Cloud Technologies in Education (CTE 2019), Kryvyi Rih, Ukraine, December 20, 2019. CEUR Workshop Proceedings Vol. 2643. Pp. 119-133 http://ceur-ws.org/Vol-2643/paper06.pdf 